\title{
A política de desenvolvimento no Estado do Paraná: limites e possibilidades de uma trajetória alternativa
}

Demian Castro*

Em 2003, embora dentro dos limites legais da lei de responsabilidade fiscal, a situação fiscal do estado do Paraná era delicada, já que emergia de um período de grave comprometimento das receitas tributárias com blocos de interesses políticos e econômicos fortemente identificados com as finanças globais e seus representantes locais. Existia um estoque de dívida negociada junto ao Banco Central a qual, da mesma forma que para a grande maioria dos estados brasileiros, estabelecia e - ainda estabelece - pesados encargos futuros comprometendo a política fiscal de recorte estadual.

Em conseqüência do ciclo político do governo anterior, a combinação de privatizações, concessões, atração de empresas automobilísticas com benefícios fiscais e parafiscais, além de farto financiamento, entre outros fatores, ajudava a definir um cenário de obstáculos e resistências para um novo governo que desejasse elaborar e executar um conjunto de políticas públicas identificadas com os setores da sociedade mais prejudicados pelos longos anos de crise, inflação e adesão oportunista às forças da globalização. Parte do desafio que se impunha nessa época era o de recuperar graus de autonomia política e fiscal capazes de sustentar um caminho assentado numa via nacional e popular, mas não divorciado dos "novos" atores internacionais.

É possível afirmar que a questão superava em muito os termos comumente evocados quando se fala na necessidade de um "ajuste fiscal". Ao mesmo tempo, as energias governamentais iriam ser consumidas em dois tipos de ações: umas, ligadas à implementação de novas políticas públicas; as outras, focadas na tentativa de reverter contratos, concessões e licitações prejudiciais ao governo e ao interesse geral. Naquele momento, tudo levava a crer que o governo federal seria um grande aliado na estratégia que se descortinava; depois, a permanência da política de acalmar os mercados mediante mega juros e a real politik do governo acabaram revelando a existência de um arranjo de forças aparentemente imune à mudança e sempre vigente na formação social brasileira.

Após mais de quatro anos é possível afirmar que o governo estadual apresenta, numa visão holística de seus principais programas, um caráter mais autêntico e coerente com os anseios políticos dos seus cidadãos eleitores do que o conjunto apresentado pelo governo

\footnotetext{
* Professor Adjunto do Departamento de Economia da Universidade Federal do Paraná (UFPR). Endereço eletrônico: demian@ufpr.br
} 
federal à sociedade brasileira. Esta constatação talvez revele a maior limitação do alcance da política de desenvolvimento estadual, qual seja: seu caráter isolado e carente de um ambiente federativo marcado pela coordenação e convergência política, incapaz de estabelecer metas conjuntas.

Convém mencionar alguns dos grandes vetores de questões que ajudam a entender o sentido da política de desenvolvimento do Paraná entre 2003 e 2007, destacando quatro. Primeiro, a existência de um conjunto amplo de problemas sociais que se originam num persistente processo de desestruturação do mercado de trabalho; segundo, nos limites estaduais, a identificação de um processo de concorrência perverso, numa dinâmica de baixo crescimento econômico que favorece a concentração e a internacionalização da economia, deixando no caminho milhares de empresas domésticas; terceiro, um acentuado processo de esvaziamento regional expresso em uma mancha de pobreza, englobando dezenas de municípios paranaenses, com baixíssimo IDH, que se sobressai na Região Sul do país; quarto, reforço na capacidade de investimentos em infra-estrutura elétrica, rodoviária e na logística do setor exportador.

De modo geral, as ações que surgem a partir dessas questões envolvem: política tributária vinculada ao principal tributo estadual, o ICMS; redirecionamento dos gastos orçamentários ou reforço de certas funções sociais; a utilização com finalidades sociais de tarifas cobradas por empresas de utilidade pública além de retomar o papel histórico da principal empresa estadual, a COPEL, na realização de investimentos.

Resumidamente, este seria o escopo da política fiscal adequada à estratégia de desenvolvimento do governo estadual. Deve-se reconhecer que as operações de crédito externas e internas encontram-se fortemente restringidas pelo endividamento pregresso do Estado, gerado durante o ciclo político anterior ao atual governo e inédito na história do Paraná. Portanto, independentemente da liquidez internacional, a capacidade de endividamento do Estado encontra-se restringida pelo endividamento negociado junto ao Banco Central do Brasil. Certamente, caso fosse examinada a capacidade de pagamento do Estado, à luz dos indicadores econômicos mais recentes, essas restrições ao endividamento deveriam ser relaxadas.

A seguir serão apresentadas algumas das principais ações/ programas retirados do portal eletrônico do governo do Estado do Paraná. Observe-se que estas ações não esgotam o universo dos programas governamentais, mas em comum guardam a característica de estarem 
orientados aos já citados setores mais desfavorecidos e são representativos da opção política do governador.

No campo da política tributária estadual pode ser destacado o seguinte: a) partindo do pressuposto de que arrecadação no Estado é fortemente concentrada, maior foco na fiscalização das maiores empresas contribuintes, públicas e privadas, instaladas no Estado; b) uma política de incentivos fiscais baseadas no favorecimento a micro e pequenas empresas (isenção e diminuição de ICMS para 77\% dessas empresas); c) diminuição de 18\% para 12\% o ICMS cobrado a empresas paranaenses ou brasileiras; d) diminuição de $18 \%$ para $7 \%$ do ICMS cobrado de certos segmentos da construção civil; e) diminuição de 12\% para 7\% do ICMS cobrado das empresas responsáveis pela cesta básica; f) diminuição de 18\% para 12\% do ICMS cobrado das empresas paranaenses de água mineral; e g) estimulo à instalação de empresas em regiões de baixo dinamismo econômico mediante a dilatação do prazo de pagamento de ICMS para até oito anos e para até quatro anos para o recolhimento do imposto sobre energia elétrica (Bom Emprego Fiscal). Para reforçar essas opções de incentivos, o governo do Estado apresenta e critica duramente, num portal temático, os custos fiscais dos contratos assinados pelo ciclo político anterior com a Renault.

No campo dos programas sociais cabe destacar o Leite das Crianças, implementado no primeiro mandato do governador Roberto Requião, entre 2003 e 2006. Esse programa atende 161 mil crianças e, segundo informações da Secretaria Estadual de Saúde, é responsável pela queda em 90\% da desnutrição infantil no Estado. Segundo informações obtidas no portal do governo, houve aumento expressivo nos gastos com função saúde. Menciona-se, também, o processo de regionalização da infra-estrutura hospitalar e dos atendimentos com a construção de hospitais regionais, pronto socorros, postos de saúde e ambulatórios nas regiões mais carentes do Paraná.

Dois programas destinados às famílias de baixa renda apresentam resultados relevantes e, certamente, constituem elos complementares das políticas federais de combate à pobreza, notadamente o programa bolsa-família, que trata dos programas Luz Fraterna, pelo qual é fornecida energia gratuita para quem consome até 100 quilowatts por mês, atendendo aproximadamente um milhão de paranaenses.

Sempre é bom lembrar que, na década de noventa, em meio aos processos de privatizações que ocorriam na América Latina, bancos de desenvolvimento multilaterais, entidades interessadas em assumir o controle de serviços de utilidade pública e, de modo geral, o mainstream do pensamento econômico, defendiam a importância de anular tarifas 
subsidiadas e de estipular cobranças universais baseadas nos custos de produção. Ao mesmo tempo, o limite de 100 quilowatts obriga a pensar a respeito da dimensão da pobreza, já que esse patamar torna o banho quente um luxo a ser seriamente dosado. O outro programa é a Tarifa Social da Sanepar pela qual 318 mil famílias recebem gratuitamente água e esgoto tratados.

Outras ações que poderiam ser consideradas mais reativas e pontuais, ajudam a configurar a política de desenvolvimento. Cita-se o contencioso envolvendo o governo do Estado, as concessionárias de rodovias e os pedágios cobrados, considerados abusivos pela grande maioria dos usuários. O governo implementou em resposta aos setores rodoviários com pedágios um programa de recuperação de malhas rodoviárias que permitam aos usuários transitarem gratuitamente dando conta dos mesmos destinos com pouca alteração de quilometragem, denominado "Caminhos Alternativos". Independentemente da boa intenção é mister afirmar que, sob a ótica econômica, esse programa não deixa de ser questionável, pois a duplicação de caminhos na área de infra-estrutura rodoviária não deriva de uma saturação das estradas por excesso de trânsito, mas sim, ocorre em conseqüência de contratos leoninos para o interesse público, os quais acabam vedando parte da capacidade produtiva disponível.

$\mathrm{Na}$ área de saneamento, o governo retomou o controle acionário da Companhia de Saneamento do Estado do Paraná - SANEPAR - numa operação que foi intensamente questionada pela mídia e as empresas afetadas pela perda de poder. $\mathrm{Na}$ área de energia, além de recuperar financeiramente a Companhia de Energia Elétrica do Paraná (COPEL), merece destaque a disputa travada, e ganha, envolvendo contratos perversos para construção e operação de usinas termoelétricas. Hoje, a COPEL comanda a construção de duas usinas hidroelétricas no complexo Jordão e cobra a tarifa mais baixa do Brasil.

Outra disputa política notável, com claras conseqüências econômicas, é a que tenta garantir que o Paraná seja um espaço livre de soja transgênica, confrontando a principal empresa multinacional produtora de sementes, a Monsanto. Mencione-se também a definição de um piso salarial regional de $\mathrm{R} \$ 437,00$ e a criação do Fundo de Aval, visando facilitar o acesso ao crédito aos pequenos produtores rurais.

A Lei de Diretrizes Orçamentárias para o exercício financeiro de 2007 constitui uma boa referência para visualizar as linhas de ações (5) do governo e a totalidade dos programas (25) que integram a estratégia de desenvolvimento. 
A seguir serão discutidas algumas questões que limitam o alcance das políticas de desenvolvimento subnacionais as quais, notadamente, se sustentam em recortes de políticas fiscais fortemente nucleadas na utilização do ICMS.

1. A política fiscal é parte constitutiva da política macroeconômica de um país e, como tal, apresenta uma dimensão nacional. Entretanto, numa federação, são as esferas de governo federal, estadual e municipal que perfazem, através das suas ações, a política fiscal. Por um lado, é o governo federal que define a política macroeconômica, em particular, a política cambial e a política monetária e estabelece o espaço, o papel e a relevância da política fiscal. Por outro lado, as esferas de governo podem, (re) ativamente, tentar estabelecer "suas políticas" usando o poder tributário permitido pelo pacto federativo e direcionar a parcela do gasto correspondente, conforme prioridades previamente estabelecidas por cada um dos governos subnacionais. Este processo de definição de uma política fiscal de recorte menor que o nacional não diz respeito, única e exclusivamente, ao chamado campo da discricionariedade pois, mesmo no âmbito das obrigações constitucionais, os governos subnacionais apresentam resultados diferenciados, não sendo trivial a qualidade da execução orçamentária e o modo como são definidas e atingidas as diversas metas. O resultado nacional desta múltipla e heterogênea gama de "políticas fiscais" pode produzir resultados aquém dos esperados dado o volume conjunto de recursos aplicados na área fiscal por todas as esferas de governo em virtude, principalmente, da existência de um dado genético da federação brasileira, gerador de níveis muito baixos de cooperação e coordenação, dificuldade crônica de estabelecer metas conjuntas e consensos políticos abrangentes. Neste caso, os estados e os municípios em competição maligna estariam simplesmente anulando-se reciprocamente. Este resultado sub-ótimo é potencializado num cenário marcado pelo baixo crescimento econômico e pela execução por parte do governo federal de uma política fiscal pouco ativa, nacionalmente incapaz de atenuar as desigualdades inter e intra- regionais do País. De modo complementar, o sistema tributário e seu marco legal podem apresentar características que venham a favorecer o aprofundamento da competição predatória entre as partes. É possível afirmar que a qualidade ou alcance da política fiscal de uma Nação depende, principalmente, de dois grandes vetores: primeiro, da política macroeconômica e, segundo, das relações federativas forjadas ao longo da história.

2. Durante a década de noventa, em resposta à crise fiscal e financeira do Estado, houve uma mudança profunda no padrão de financiamento dos governos estaduais que tiveram que privatizar empresas públicas estaduais e instituições financeiras públicas estaduais 
como parte da renegociação das suas dívidas. A partir dessa renegociação e da lei de responsabilidade fiscal os governos estaduais enfrentaram o que podemos denominar de "estreitamento fiscal", dados os limites aos novos endividamentos e, também, como conseqüência do amplo processo de privatização. Na situação atual, o tributo estadual constitui praticamente a única fonte de financiamento das políticas fiscais de recorte estadual.

3. A política macroeconômica do governo brasileiro, em execução desde 1999, apresenta fortes traços de continuidade em relação a alguns dos seus principais fundamentos e condicionantes. Guiada pelo sistema de metas de inflação e de superávit primário, a política em prática nos últimos anos visa garantir a estabilidade, que passa pela entrada de dólares no país, e a sustentabilidade da relação Dívida Pública Interna/ PIB. Dentro desta perspectiva, o resultado mais relevante que se espera alcançar com a política fiscal é financeiro e seu ajuste permanente visa garantir níveis de superávit compatíveis com variáveis que não determina. Além disto, o sentido da política fiscal deve acenar para a formação de expectativas dos agentes privados, o que significa que, mais do que os resultados alcançados, o que interessa é a garantia da existência de um regime fiscal. Dentro desta linha, um dos cenários mais prováveis para os próximos anos aponta para a continuidade desta política econômica, com a busca permanente de resultados primários, embora a execução orçamentária nos níveis atuais mostre, cada vez com maior clareza e dramaticidade, seus limites políticos. Assim sendo, parece prudente imaginar que para o futuro próximo o mais provável é esperar mudanças pendulares de grau em função das pressões políticas internas e, principalmente, dos mercados financeiros internacionais sem, contudo, imaginar uma mudança do regime fiscal.

4. No processo de descentralização fiscal brasileiro, os estados não têm desempenhado um papel relevante, ajudando a constituir uma via marcada univocamente pelas relações entre a União e os municípios. Paradoxalmente, a guerra fiscal que os governos estaduais protagonizam impede o desenvolvimento de relações horizontais marcadas pela cooperação e coordenação, obstaculizando a construção coletiva de instâncias estaduais em condições de regular e melhorar o movimento de municipalização. Observa-se, portanto, que os governos estaduais não apresentam estratégias sistêmicas de relacionamento e lide com os municípios, deixando de desenvolver um campo profícuo para ampliar a qualidade da política fiscal de corte estadual.

5. Caso o regime fiscal continue e a política macroeconômica sofra poucos ajustes é possível pensar que o "ativismo fiscal" dos governos estaduais será bastante limitado e fortemente determinado pela trajetória do principal tributo estadual, já que continuarão 
restringidas as possibilidades de expandir o endividamento. Observe-se que houve nos últimos anos algum aumento da participação relativa do governo federal nas receitas tributárias disponíveis, principalmente através das contribuições. Também, é importante ressaltar que os estados da Região Sudeste e da Região Sul vêm perdendo participação relativa na arrecadação de ICMS, embora a tendência seja mais acentuada na Região Sudeste. O Paraná apresenta queda na participação quando se comparam as décadas de oitenta e noventa, após 2000 apresenta alguma recuperação.

6. A ação dos governos estaduais mais efetiva para inverter ou atenuar o processo em curso de fragmentação regional com a formação de espaços vazios e outros altamente concentradores e receptores de pressões populacionais, necessariamente requer forte envolvimento dos municípios e, por sua vez, que estes sejam capazes de desenvolver metas conjuntas de âmbito intra- regional. O sistema político partidário brasileiro e o calendário eleitoral tendem a dificultar a realização de "consensos intergovernamentais" e isto é particularmente grave no caso das regiões metropolitanas do País. Neste sentido, é importante o esforço do governo estadual por recuperar o planejamento metropolitano e avançar no sentido de constituir as regiões metropolitanas de Maringá e Londrina.

7. Em relação à discussão sobre os limites e possibilidades da utilização do ICMS enquanto instrumento decisivo de política industrial (descentralizada?) a influenciar decisões locacionais das empresas, existe uma percepção generalizada de que a participação do estado de São Paulo na guerra fiscal anula as ações dos outros competidores. Isto é dado como sinal de esgotamento da política fiscal nos moldes dos incentivos, subsídios e benefícios. Esta percepção, de certa forma, obriga a elaborar novas políticas públicas com outros cortes setoriais e regionais, além de outro sistema de incentivos.

8. Há algum consenso em que as medidas adotadas de isenção tributária no Estado são horizontais e reativas (em relação ao que fazem outros estados da federação). Ao mesmo tempo, aponta-se a importância de serem realizados estudos de avaliação regional dos impactos das ações nos campos tributário e tarifário (foram mencionados para efeito de monitoramento e avaliação o FDU, o FDR e o ICMS ecológico). Por outro lado, é de suma importância combinar a abordagem setorial dos gastos com a abordagem espacial, o desafio posto pelos “vários Paranás" é o de melhorar justamente a visão espacial dos gastos públicos e das medidas de incentivo tributário.

9. Para potencializar as políticas de desenvolvimento subnacionais, especialmente aquelas orientadas aos segmentos sociais mais desprotegidos e às áreas em vias de 
esvaziamento, é crucial a construção de consensos entre os governos estaduais visando a execução de ações coordenadas e, desta forma, intentar preencher um vácuo no processo de descentralização brasileiro. O Fórum Fiscal dos Estados Brasileiros é um espaço relevante para a construção de enfoques federativos convergentes.

10. É necessário articular a política fiscal estadual com os arranjos produtivos locais (APL's), os quais estão ancorados, em parte, na visão do desenvolvimento regional endógeno. Entretanto, não deve menosprezar-se o fato de que muitos APL's por serem demasiado específicos ou limitados ou localizados em regiões pouco integradas podem apresentar impulsos endógenos desprezíveis. Numa visão mais sistêmica trata-se de articular os instrumentos fiscais disponíveis, numa abordagem espacial, com o Plano Estadual de Desenvolvimento Regional.

11. Ainda como parte deste processo de articulação entre a política fiscal estadual e o território, deve trabalhar-se a seguinte questão: como compatibilizar uma política fiscal essencialmente horizontal (que tende a tratar simetricamente todos os agentes) com a necessidade de pôr em prática ações heterogêneas para regiões diferentes? A espacialização das iniciativas fiscais pode ser um dos caminhos para superar o mito do engessamento orçamentário.

12. Para além da preocupante situação de inúmeros municípios submetidos ao forte processo de esvaziamento e decadência econômica, observa-se que a Região Metropolitana de Curitiba concentra população e demandas sociais por serviços públicos em escalas dramáticas, numa dimensão muitas vezes superior a dezenas de municípios do interior, ou seja, a política de desenvolvimento regional não deve esquecer que a RMC, que concentra a maior parte do valor adicionado do Estado, é também o epicentro de fortes tensões sociais derivadas de problemas ou questões de índole nacional e que, a qualquer momento, podem explodir. Este aspecto abre a discussão para um campo específico das relações federativas do País: o relacionamento entre os governos estaduais e os respectivos espaços metropolitanos.

Em suma, ao avaliar políticas de desenvolvimento subnacionais é preciso considerar, para além de seus méritos econômicos, sociais e ambientais que a alternância do ciclo político, o comando macroeconômico do governo federal e seu regime fiscal e, não menos importante, a baixa propensão à cooperação e planejamento conjunto das esferas federativas limitam seus impactos e permanência. 


\section{Referências bibliográficas}

Castro, D. "Mudança, permanência e crise no setor público paranaense: um balanço da trajetória estadual na segunda metade do século XX". Tese de Doutorado, IE/ UNICAMP, Campinas, SP, 2005.

IPARDES. "Os vários Paranás: estudos socioeconômicos e institucionais como subsídios aos planos de desenvolvimento regional".

Lei Número 15.226 DE 25 DE JULHO DE 2006. "Diretrizes orçamentárias para o exercício financeiro de 2007".

Lei Número 15.539 DE 22 DE DEZEMBRO DE 2006. "Lei orçamentária para o exercício de 2007”'.

Lei Número 14.276 DE 29 DE DEZEMBRO DE 2003. PPA 2003-2007.

Portal do Governo do Estado do Paraná. www.parana.pr.gov.br. Acessado em 20.06.07.

www.gestaodinheiropublico.pr.gov.br 
